
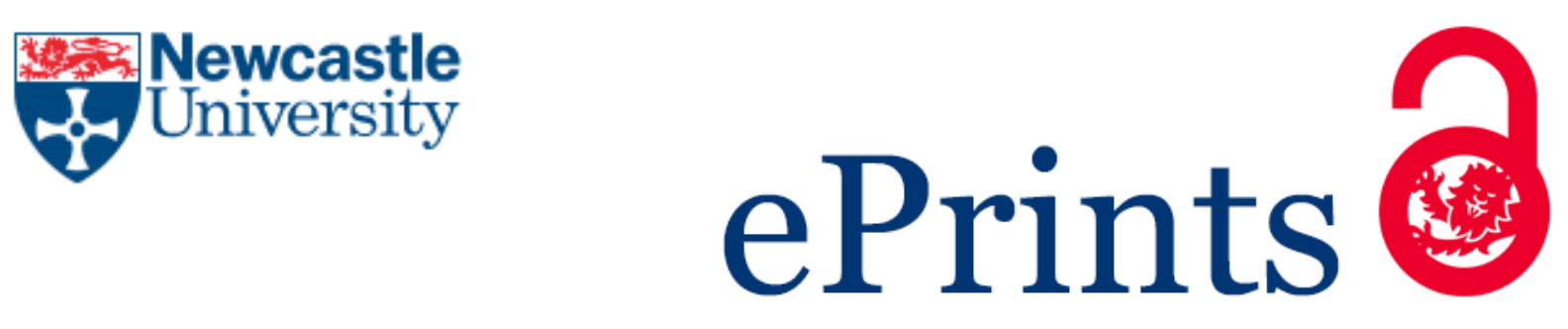

Ferrari C, Migliardi A, Tei A.

A bootstrap analysis to investigate the economic efficiency of the logistics

industry in Italy.

International Journal of Logistics Research and Applications 2017,

http://dx.doi.org/10.1080/13675567.2017.1353597

\title{
Copyright:
}

This is an Accepted Manuscript of an article published by Taylor \& Francis in International Journal of Logistics Research and Applications on 18/07/2017, available online:

http://www.tandfonline.com/doi/full/10.1080/13675567.2017.1353597.

DOI link to article:

http://dx.doi.org/10.1080/13675567.2017.1353597

Date deposited:

$18 / 07 / 2017$

Embargo release date:

18 July 2018

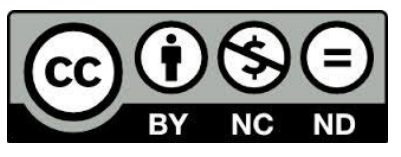

This work is licensed under a

Creative Commons Attribution-NonCommercial-NoDerivatives 4.0 International licence 


\section{A bootstrap analysis to investigate the economic efficiency of the logistics industry in Italy ${ }^{1}$}

Claudio Ferrari - Department of Economics, University of Genoa

Andrea Migliardi² - Bank of Italy

Alessio Tei - School of Marine Science and Technology, Newcastle University

\section{Abstract}

As argued by literature and consultancy reports, logistics enhances both productivity and competitiveness of several manufacturing supply chains. The analysis of the efficiency trends of logistics providers may shed light on some relevant aspects that can impact on the competitiveness of national industrial systems. Thus, the paper focuses on the Italian logistics supply, shedding lights on the distribution of the efficiency level within the logistics sector and its causes.

The analysis is based on a two-stage methodology aiming at estimating the Italian logistics firms' efficiency and defining some characteristics impacting on the efficiency level. At first we implement a DEA model based on balance-sheet data, for the period 2006-2012, then an econometric regression is performed in order to identify the effects of main companies' characteristics on firms' efficiency. According to our results, size and geographical location are two of the most impacting variables explaining the efficiency score of the Italian logistics providers.

Keywords: logistics performance, efficiency, two-stage analysis, Italian logistics

\footnotetext{
${ }^{1}$ The views expressed in this paper are those of the authors and do not involve the responsibility of the Bank of Italy.

2 Just after the first revision of the manuscript Andrea Migliardi passed away. He was a valuable economist, a dedicated worker and a pleasant friend. This paper intends to honour his memory.
} 


\section{Introduction}

Logistics consists in the "process of planning, implementing, and controlling the efficient, cost effective flow and storage of raw materials, in-process inventory, finished goods and related information from a point of origin to the point of consumption for the purpose of meeting customer requirements" (Council of Logistic Management 1998). The relationship between logistics and production is quite strict because logistics doesn't only act as industry itself but mainly it serves other industrial sectors (e.g. Skjoett-Larsen 2000; Stecke and Zhao 2007) adding value to production outputs, encountering the changing market needs and assuring that goods are given where and when necessary, with a reliable, safe and efficient distribution (e.g. Fugato et al. 2008). Moreover, logistics might become a strategic element for small firms development - as underlined by Halley and Guilhon (1997) and Groer et al. (2008) - providing advanced innovative services able to increase the firm remunerability (e.g. Altug and Aydiniliyim 2016).

All the goods that we daily consume take advantages of the logistics services. Economic globalisation, enhanced by the dramatic reduction of unitary transportation costs, has increased the relevance of logistics and its impact on the competitiveness (e.g. Clark et al. 2004; Clifton et al. 2006; Bolumole et al. 2015) as well as on sustainability (lannone, 2012 and Bottani et al. 2015) of manufacturing industries. Despite this, as argued by Chow et al. (1994) and several authors afterwards (e.g. Fugate et al. 2010), a definition of logistics performance - and its related measure - is not easy to be universally identified due to the heterogeneity of activities included in the logistics sector. Nevertheless, as underlined by Fugate et al. (2010), the efficiency and the effectiveness of the logistics activities are key elements in order to increase the performance of the related sectors. Moreover, Griffis et al. (2007) pointed out how the importance of measuring performance of logistics providers is crucial for their own success in the long run. Wanke (2012a, $2012 \mathrm{~b}$ and 2010) underlines the importance of evaluating determinants in logistics performance in order to better identify environmental variables that might foster logistics activities.

As argued by Pagliaro (2013) on a book studying Italian logistics: "without the network [...assured by logistics activities] our Country has grown till it was possible" but without an expansion of this "network" economic growth is harder to realize. The recent economic crisis showed some weaknesses in the Italian industrial 
organization. These elements already existed but they were previously hidden by the GDP and industrial growth and today the lack of efficiency in the logistics sector is becoming more evident than in the past (Confetra 2011). Moreover, several authors (e.g. Bottani et al. 2015) underline how logistics sector is strategic to foster sustainable growth of specific industrial districts. Given the current role for logistics, the added value depends on the ability to provide solutions that enhance the service efficiency across the overall supply chain. This aspect depends mainly on the range and the quality of higher value added services offered by logistics providers to the industrial sector. As stressed in Ferrari et al. (2013), Italian logistics firms register a softly decreasing trend for efficiency also due to their small size (on average) that prevents the exploitation of scale economies. Moreover, Ferrari et al. (2013) show that some variables like the legal form of companies and their size may become strategic elements for efficiency gains. The above-mentioned paper just found current logistics efficiency scores (through a Data Envelopment Analysis [DEA]), linking it on some operational or managerial factors. While the importance of the logistics sector is normally well recognised in literature and by industrial associations (e.g. Confetra 2011), there are currently few studies aiming at understanding current performance patterns in the Italian logistics industry. Moreover, none of these studies tried to identify companies' characteristics and their effect on the industry performance. Current paper tries to fill this gap. The goal of the paper is achieved through a two-stage methodology: the first stage (a DEA) will identify efficiency scores for every Italian firms included in the sample while the second stage (a regression) will link the efficiency results to companies' characteristics in order to understand the role that some firms' elements may play in conditioning or increasing the sample efficiency. In order to do it a large sample of Italian logistics providers has been studied as well as a period of time that overcome the economic crisis allowing us to test the response of logistic sector to the financial crisis.

The sample consists of 139 logistics firms headquartered in Italy whose primary activity is recorded in the Italian Chamber of Commerce database (i.e. Cebil-Cerved) as logistics operations (i.e. NACE code n.522922). The mentioned database collect all the balance sheets of every Italian company and our sample represent about $20 \%$ of the overall companies representing the Italian logistics sector. Since the official database is characterised by a "registration" lag before including the data of (mainly) smaller firms, missing values are 
common for the most recent years. For this reason, the investigation stops at the 2012 financial year. On the other hand, 2006 data are used in order to have also information pre-economic crisis. Moreover, the sample has been built in order to mainly consider the companies that are always active in the whole considered period. This choice has been made in order to evaluate the effects of the different characteristics.

Fig. 1 exhibits the distribution of the sampled firms on the Italian macro-regions. The majority is located in the North of the Country (equally distributed in the North West and North East regions), while only a fifth of the sample is localised in the Southern of Italy and the lowest share is located in the Centre. The distribution of revenues collected by our sample confirms a relevant concentration in the North West (see fig. 2, referred to 2012) that accounts for over $60 \%$ of global revenues; North East (16\%), Centre (14.6\%) and South (7.8\%) follow.

\section{Figure 1: Sample distribution}

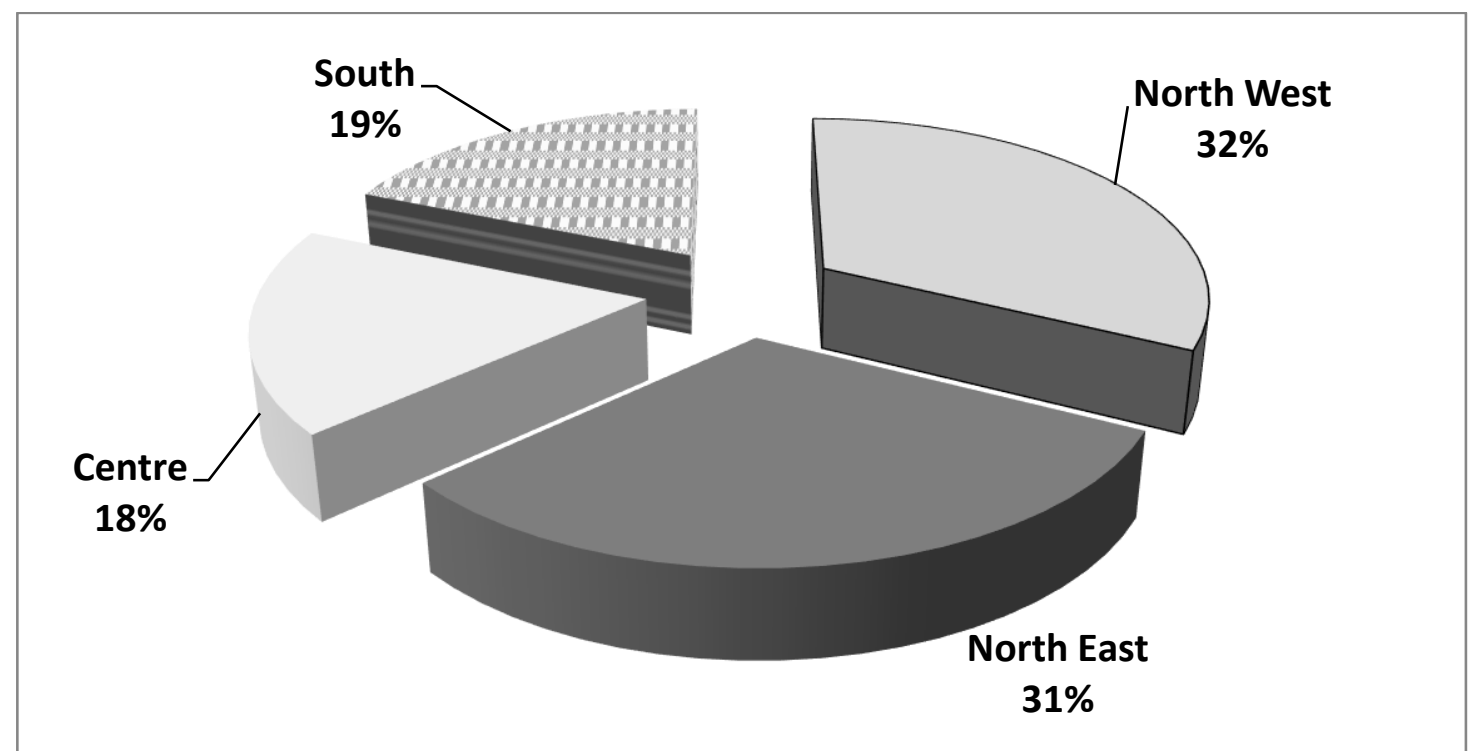

Source: Our elaboration on Cebil-Cerved data. 


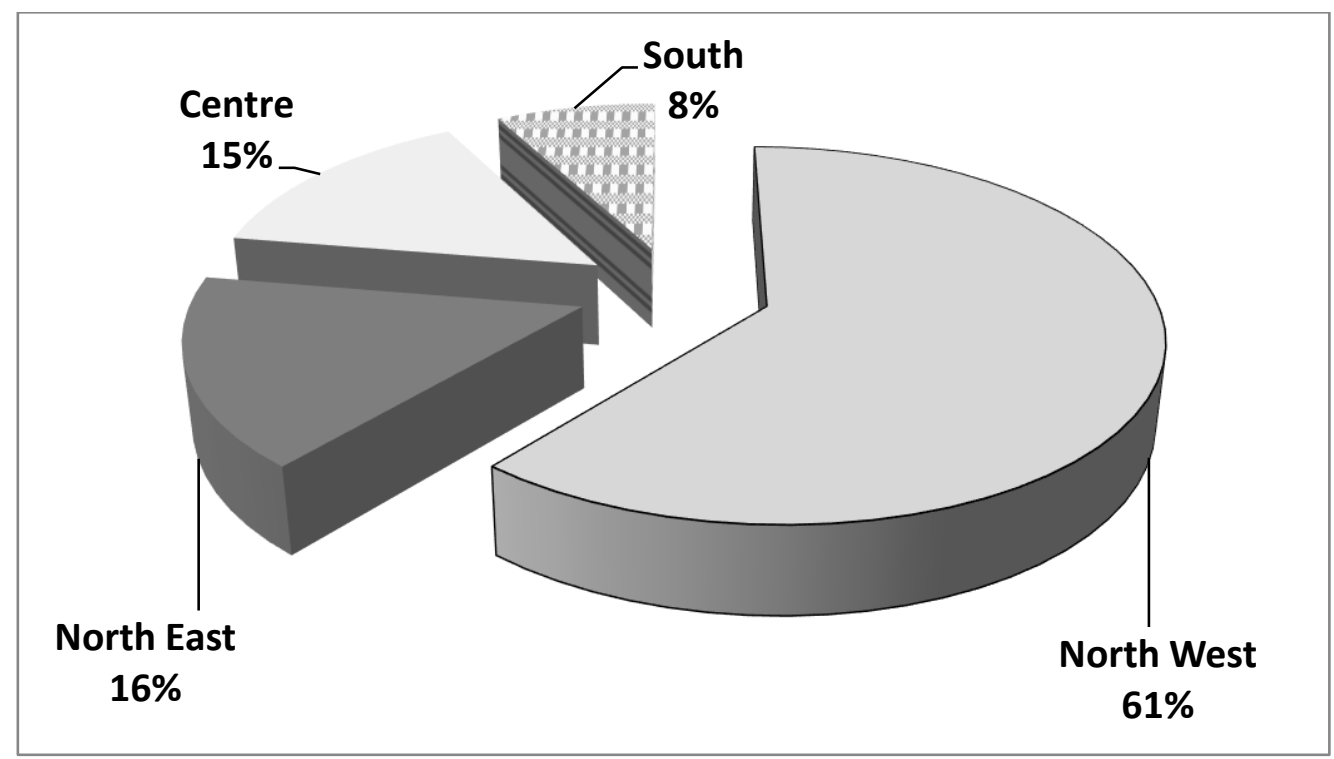

Source: Our elaboration on Cebil-Cerved data.

The impact of the economic crisis on the logistics sector is testified by the fact the in all macro-regions, but North West, the number of firms recording a volume of revenues higher than the regional mean has been decreasing since 2006.

\section{Literature Review}

In the recent years, several papers (e.g. Marchet et al., 2016; Wanke 2012a; Dayou 2010; Wanke 2010; Liu e Fu 2009; Zhou et al. 2008; Min and Joo 2006 and 2009) have focused their attention on the efficiency in the logistics industry, exploiting no parametric techniques, such as DEA, in order to estimate the optimal quantities of inputs and outputs of efficient units, taking into account the potential heterogeneity of the typical mix of activities performed by logistics operators.

Wanke (2012b and 2010) carries out an efficiency analysis on Brazilian logistics firms aiming at identifying the main determinants, while the other cited authors focus on Chinese firms, either in general terms - Min e Joo (2006 and 2009) and Zhou et al. (2008) - or trying to define specific impact factors. For example, Dayou (2010) analyses listed companies aiming to define a link between efficiency and quotation trend, while Liu and Fu (2009) study how technology impacts on efficiency. Momeni et al. (2015) proposed a multi- 
objective DEA model in order to identify the efficiency of third party reverse logistics provider in supply chain and they tested it for a case study. Recently, Marchet et al. (2016) linked efficiency gains to innovation parameters through a DEA applied to the Italian 3PL market. Similarly Wanke et al. (2014) and Wanke (2014) focus on the trucking industry demonstrating similar patterns in terms of efficiency determinants.

Concerning the Italian market, Ferrari et al. (2013) used DEA to get the efficiency trend both for a closed and for an open sample of Italian logistics firms: the authors found that some firms' characteristics (like type of corporation, size and geographical localization) typically match with higher efficiency levels without looking at clear empirical connections of these links.

Thus, previous studies on the logistics markets have been generally directed to rank different providers or to correlate efficiency levels to some specific variables more than discovering aspects that may influence the achievement of a specific performance. Considering past researches on the logistics sector, efficiency studies are normally developed through a one-stage analysis, either parametric (e.g. Stochastic Frontier Analysis [SFA]) or no parametric (e.g. DEA); as said DEA is the most common research tool given its flexibility. While to analyse other sectors, two-stage analysis have been already used (e.g. ), at the best of our knowledge only few papers (e.g. Wanke 2012) applied similar methodologies to the logistics industry and none of them to the Italian market. Thus, in respect to existing literature, our approach can better identify current critical issues related to the low efficiency level of the Italian logistics sector.

The possibility to analyse the role and the impact of the so-called environmental variables on efficiency represents a well-debated open question (e.g. Barnum and Gleason 2008; Bracalente and Polinori, 2010). Some authors apply a two-stage procedure: the efficiency scores - worked out at the first stage with traditional techniques - are regressed on possible environmental or firms' specific variables at the second stage. To this end, while some papers exploit traditional econometric models (e.g. Buzzo Margari et al. 2007; Balaguer-Coll et al. 2007), others shed light on possible distortions due to the potential correlations among these explicative variables and the efficiency levels. For instance, Kumbhakar and Lovell (2000) highlight some econometric problems if the estimated efficiencies (through SFA) are regressed against other exogenous variables in a second-stage regression. 
To overcome these shortcomings, starting from the seminal paper written by Simar and Wilson (2007), potential distortions are corrected by using at the second stage some bootstrapping procedures. Recently Bergantino et al. (2013) and da De Oliveira and Cariou (2014) adopted this approach in the transport field: while the former studies the role for transportation infrastructures on the efficiency of R\&D at a regional level; the latter investigates the determinants of the efficiency of container terminals. Following this strand of literature, the present paper exploits this technique in order to better understand the role of some explicative firms' specific variables in determining the efficiency of logistics sector for a seven years period (2006-2012).

\section{Methodology}

Our analysis adopts a two-stage procedure: at the first stage efficiency scores are found through the Data Envelopment Analysis (DEA) with variable returns to scale (VRS). The variable returns to scale are preferred for the selected sample, taking into account the differences in size of the analysed logistics firms (we carried out also the analysis with the constant returns to scale [CRS]; the results are consistent to the those shown in this paper); and at the second stage a truncated regression is used with bootstrapping $(2,000$ bootstrap replications) for the selected firms, in order to estimate the links among the efficiency scores and some firms' specific variables.

For both operational and financial efficiency definitions, most of the literature uses main operational or financial inputs and outputs. While some authors (e.g. Wanke 2012a) use physical operational values (e.g. work force, warehouses), authors that are interested in financial performance normally use balance sheet data (e.g. Zhou et al. 2008). In accordance with previous studies, efficiency scores are then based by main financial items: labour costs, material costs, services costs and tangible fixed assets as main inputs and revenues as main output. Since the second stage of the analysis aims at linking efficiency to main firms' specific attributes, some of the operational characteristics have been considered (e.g. internationalization, specialization, age, type of corporation and size). 
The selected firms constitute a cohort (or a closed sample of firms) characterised by the availability of data for the overall considered period, as this time windows analysis drives to a homogenous trend of comparable outcomes.

\subsection{The data}

The model uses information about economic and financial variables and variables characterising the environment where firms operate. As recalled, economic and financial data refer to the tangible fixed assets and to the main operating costs: labour, material and services costs. Table 1 shows the descriptive statistics concerning the balance sheet data used for the DEA. The North West of Italy exhibits a mean level for revenues well above the other Italian regions. Moreover, North Western average levels for other variables, with the exception of tangible fixed assets, always overcome the values registered by the other Italian regions. The general trend cannot considered positive with high level of standard deviation in all the main Italian regions: this latter fact underlines the heterogeneity of the group of companies included in the study. 
Table 1: descriptive statistics

\begin{tabular}{|c|c|c|c|c|c|c|c|c|c|c|c|c|c|c|c|c|c|c|c|c|}
\hline \multicolumn{21}{|c|}{2006} \\
\hline & \multicolumn{4}{|c|}{ Revenues } & \multicolumn{4}{|c|}{ Tangible Fixed Assets } & \multicolumn{4}{|c|}{ Material Costs } & \multicolumn{4}{|c|}{ Labour Costs } & \multicolumn{4}{|c|}{ Services Costs } \\
\hline & NW & $\mathrm{NE}$ & $\mathrm{CE}$ & S & NW & $\mathrm{NE}$ & $\mathrm{CE}$ & S & NW & $\mathrm{NE}$ & $\mathrm{CE}$ & S & NW & $\mathrm{NE}$ & $\mathrm{CE}$ & $S$ & NW & $\mathrm{NE}$ & $\mathrm{CE}$ & $S$ \\
\hline Avg & 23,284 & 7,122 & 8,920 & 4,241 & 1,800 & 1,787 & 1,396 & 2,056 & 2,137 & 368 & 341 & 244 & 3,425 & 1,782 & 2,013 & 590 & 17,380 & 4,680 & 6,270 & 3,371 \\
\hline MAX & 33,731 & 42,578 & 66,786 & 51,814 & 24,797 & 25,160 & 11,425 & 20,446 & 34,033 & 3,146 & 4,694 & 2,748 & 8,503 & 19,838 & 30,540 & 4,701 & 27,690 & 31,909 & 28,711 & 44,762 \\
\hline MIN & 273 & 168 & 122 & 42 & 1 & 4 & 5 & 4 & 1 & 2 & 6 & 1 & 12 & 27 & 29 & 2 & 82 & 13 & 6 & 5 \\
\hline StDev & 61,787 & 9,602 & 13,941 & 9,749 & 4,470 & 5,059 & 2,851 & 4,849 & 6,011 & 791 & 907 & 569 & 9,870 & 3,749 & 5,904 & 1,000 & 51,801 & 7,125 & 8,135 & 8,537 \\
\hline \multicolumn{21}{|c|}{2007} \\
\hline$A v g$ & 25,849 & 7,822 & 9,908 & 4,579 & 2 & 2 & 2 & 2 & 3,250 & 417 & 352 & 272 & 4 & 2 & 2 & 700 & 17,918 & 5,163 & 7,107 & 3,721 \\
\hline$M A X$ & 37,361 & 47,095 & 76,961 & 55,835 & 29 & 26 & 22 & 22 & 50,982 & 3,673 & 4,545 & 2,066 & 8 & 23 & 35 & 6 & 30,976 & 35,682 & 35,485 & 47,812 \\
\hline MIN & 261 & 179 & 190 & 110 & 1 & 3 & 7 & 5 & 2 & 3 & 2 & 1 & 5 & 28 & 38 & 15 & 133 & 10 & 9 & 11 \\
\hline StDev & 62,908 & 10,193 & 15,902 & 10,513 & 5,229 & 4,936 & 4,548 & 5,787 & 9,631 & 888 & 880 & 544 & 10,010 & 4,138 & 6,840 & 1,258 & 49,866 & 7,674 & 9,261 & 9,178 \\
\hline \multicolumn{21}{|c|}{2008} \\
\hline Avg & 27,747 & 8,087 & 11,274 & 5,995 & 2,596 & 2,802 & 2,597 & 5,473 & 3,482 & 508 & 496 & 392 & 4,159 & 2,212 & 2,346 & 793 & 19,281 & 5,156 & 8,243 & 4,555 \\
\hline$M A X$ & 39,635 & 48,329 & 88,449 & 72,080 & 29,568 & 29,314 & 32,258 & 61,446 & 75,909 & 3,744 & 5,228 & 3,157 & 8,679 & 23,441 & 37,236 & 6,031 & 37,996 & 36,683 & 43,070 & 61,807 \\
\hline MIN & 239 & 187 & 483 & 203 & 1 & 8 & 6 & 9 & 1 & 3 & 3 & 2 & 14 & 31 & 58 & 45 & 101 & 11 & 15 & 16 \\
\hline StDev & 70,271 & 10,109 & 18,817 & 13,652 & 5,917 & 6,728 & 6,511 & 14,203 & 12,587 & 947 & 1,078 & 784 & 10,656 & 4,281 & 7,210 & 1,240 & 55,153 & 7,522 & 11,769 & 11,828 \\
\hline \multicolumn{21}{|c|}{2009} \\
\hline$A v g$ & 25,453 & 7,190 & 12,205 & 5,206 & 3 & 3 & 2 & 6 & 2,440 & 512 & 373 & 408 & 4 & 2 & 3 & 876 & 18,070 & 4,292 & 9,017 & 3,606 \\
\hline$M A X$ & 40 & 49 & 93 & 47 & 31 & 33 & 31 & 62 & 46 & 4 & 4 & 4 & 8 & 22 & 40 & 6 & 37,191 & 37,060 & 66,000 & 37,467 \\
\hline MIN & 229 & 141 & 628 & 258 & 1 & 8 & 5 & 9 & 1 & 3 & 1 & 1 & 17 & 29 & 46 & 48 & 92 & 12 & 13 & 32 \\
\hline StDev & 62,729 & 9,370 & 21,994 & 9,188 & 5,721 & 7,433 & 6,285 & 14,426 & 7,745 & 1,015 & 819 & 901 & 9,876 & 4,088 & 7,849 & 1,214 & 49,032 & 6,754 & 15,227 & 7,445 \\
\hline \multicolumn{21}{|c|}{2010} \\
\hline Avg & 29,759 & 7,552 & 12,712 & 5,452 & 2,495 & 2,927 & 2,430 & 5,638 & 2,521 & 612 & 468 & 530 & 4,423 & 2,198 & 2,782 & 819 & 21,811 & 4,526 & 9,249 & 3,589 \\
\hline$M A X$ & 51,782 & 52,882 & 102,025 & 48,113 & 29,438 & 33,443 & 30,198 & 63,416 & 56,771 & 4,808 & 5,069 & 3,957 & 8,016 & 17,553 & 47,562 & 4 & 50,697 & 39,590 & 80,810 & 35,227 \\
\hline MIN & 247 & 140 & 452 & 223 & 2 & 6 & 7 & 4 & 1 & 2 & 1 & 1 & 1 & 32 & 92 & 47 & 120 & 11 & 17 & 40 \\
\hline StDev & 88,246 & 9,666 & 24,974 & 9,504 & 5,796 & 7,805 & 6,310 & 14,570 & 8,774 & 1,132 & 1,038 & 1,087 & 13,031 & 3,699 & 9,235 & 996 & 71,399 & 7,272 & 17,880 & 7,247 \\
\hline
\end{tabular}


2011

\begin{tabular}{|c|c|c|c|c|c|c|c|c|c|c|c|c|c|c|c|c|c|c|c|c|}
\hline \\
\hline Avg & 30,856 & 8,398 & 13,172 & 6,105 & 2,588 & 2,896 & 2,346 & 3,449 & 2,528 & 764 & 535 & 594 & 4,454 & 2,346 & 3,071 & 960 & 23,223 & 5,130 & 9,402 & 4,224 \\
\hline MAX & 57,901 & 62,511 & 110,930 & 62,304 & 30,667 & 34,145 & 25,265 & 35,254 & 58,166 & 5,342 & 5,998 & 6,018 & 7,647 & 20,274 & 53,156 & 7,639 & 57,094 & 46,318 & 81,068 & 45,863 \\
\hline$M I N$ & 255 & 139 & 541 & 118 & 1 & 1 & 6 & 4 & 1 & 3 & 4 & 1 & 11 & 42 & 107 & 50 & 105 & 9 & 22 & 38 \\
\hline StDev & 88,585 & 11,366 & 26,444 & 12,274 & 5,801 & 7,792 & 5,546 & 8,877 & 8,867 & 1,378 & 1,219 & 1,300 & 12,296 & 4,188 & 10,318 & 1,532 & 74,209 & 8,466 & 18,149 & 9,305 \\
\hline \multicolumn{21}{|c|}{2012} \\
\hline & \multicolumn{4}{|c|}{ Revenues } & \multicolumn{4}{|c|}{ Tangible Fixed Assets } & \multicolumn{4}{|c|}{ Material Costs } & \multicolumn{4}{|c|}{ Labour Costs } & \multicolumn{4}{|c|}{ Services Costs } \\
\hline & NW & $\mathrm{NE}$ & $\mathrm{CE}$ & $S$ & NW & $\mathrm{NE}$ & $\mathrm{CE}$ & $S$ & NW & $\mathrm{NE}$ & $\mathrm{CE}$ & $\mathrm{S}$ & NW & $\mathrm{NE}$ & $\mathrm{CE}$ & $S$ & NW & $\mathrm{NE}$ & $\mathrm{CE}$ & $S$ \\
\hline Avg & 30,192 & 8,716 & 12,951 & 6,687 & 2,483 & 2,921 & 3,381 & 3,214 & 2,490 & 740 & 522 & 1028 & 4,302 & 2,403 & 3,204 & 1,248 & 22,752 & 5,384 & 8,807 & 4,200 \\
\hline$M A X$ & 53,864 & 67,500 & 112,815 & 75,569 & 32 & 36,635 & 23,988 & 34,790 & 56,993 & 4,887 & 7,537 & 17,392 & 6,561 & 22,521 & 56,629 & 13,619 & 53,160 & 49,731 & 75,075 & 43,085 \\
\hline$M I N$ & 218 & 139 & 585 & 153 & 1 & 2 & 5 & 2 & 1 & 4 & 1 & 1 & 8 & 54 & 65 & 50 & 96 & 11 & 36 & 48 \\
\hline StDev & 82,157 & 12,194 & 26,300 & 14,825 & 5,768 & 7,972 & 6,988 & 8,678 & 8,671 & 1,189 & 1,486 & 3,365 & 11,235 & 4,461 & 11,002 & 2,605 & 69,265 & 9,124 & 17,136 & 9,138 \\
\hline
\end{tabular}

Source: Our elaboration on Cebil-Cerved data. Data in thousands of euro. NW- North West; NE-North East; CE-Central; S-South. 
Data in table 1 represent inputs and output for the first stage analysis. In figure 3 average trends for these variables are shown, considering the overall values per each financial source.

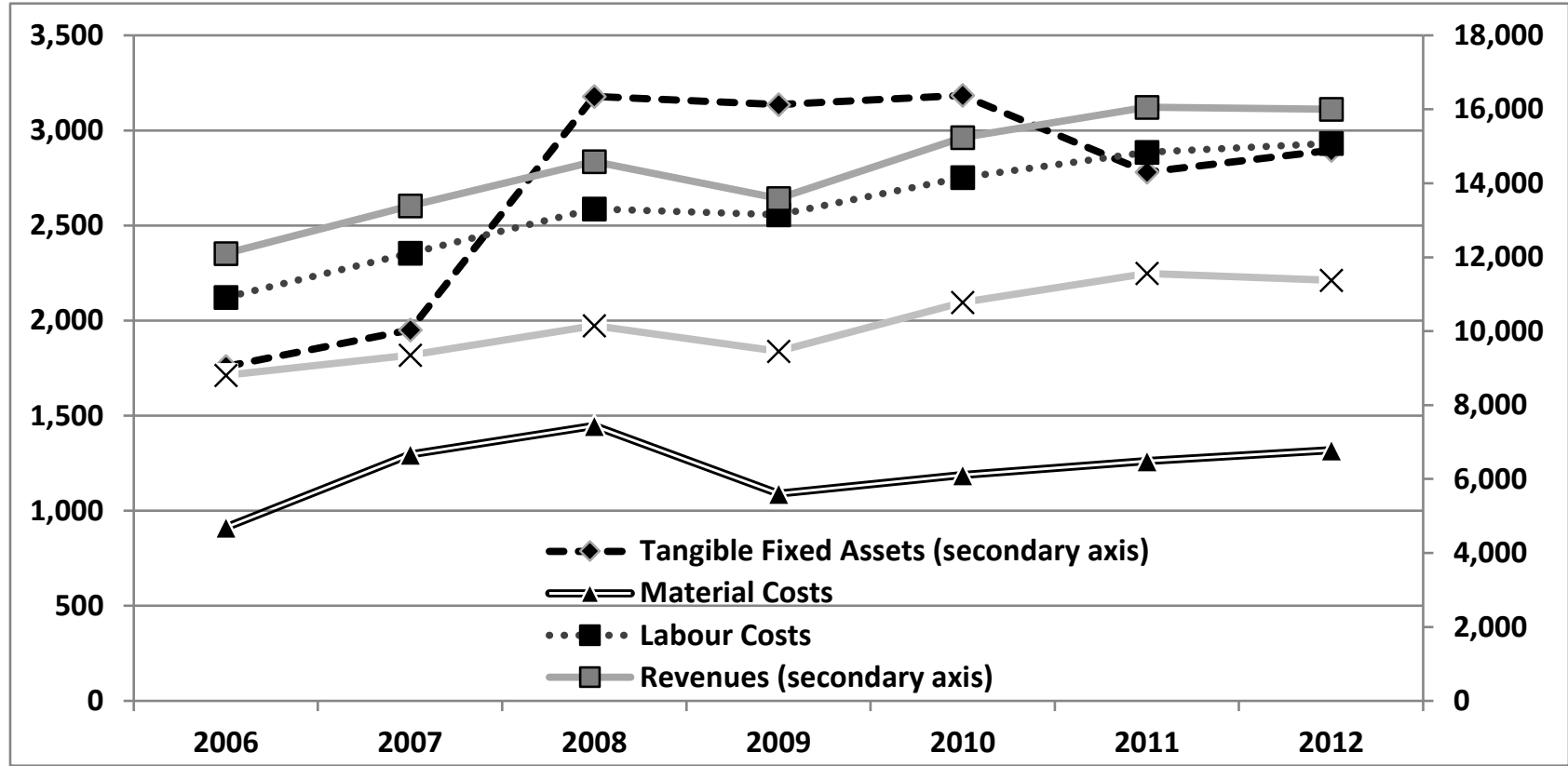

Source: Our elaboration on Cebil-Cerved data. Data in '000s of euro.

The considered variables show only a low increase during the period, mainly due to the ongoing economic crisis that is characterising Italian economy since 2008 (in 2008-2009 the crisis effects are well visible in fig.

3).

Table 2 reports the firms' specific variables used at the second stage. These variables represent company characteristics that may potentially impact on efficiency scores; at the same time, they represents also factors that could promote added value for the providers' clients. Different factors have been considered but in the current analysis only some of them have been actually implemented in the analysis: internationalization (dummy that is 1 if the selected firm controls foreign firms or dispose of stable foreign organizations or simply offers export services as detectable from the website), specialization (dummy that is 1 if the selected firm offers logistics services in favour of a specific industrial chain, while it is 0 if it offers diversified logistics services), age (continuous variable given by the difference between the foundation year 
and the reference year for each balance sheet data), size (dummy which is 1 when the selected firm size is over the sample median) and type of corporation (dummy that is 1 in case of limited corporations and 0 in case of cooperatives or consortia). Also a territorial variable is included in the model given the different regional differences currently characterising Italian economy (i.e. North West, North East, Central, and South Italy). These geographical variable represents the company's headquarter location.

Table 2: descriptive statistics for the second stage variables

\begin{tabular}{|c|c|c|c|c|c|}
\hline & Internationalization & Specialization & Age & Size & Type of corporation \\
\hline Mean & 0.22 & 0.33 & 17.18 & 0.5 & 0.83 \\
\hline Median & 0 & 0 & 12 & 1 & 1 \\
\hline 1st quartile & 0 & 0 & 9 & 0 & 1 \\
\hline 3rd quartile & 0 & 1 & 19 & 1 & 1 \\
\hline
\end{tabular}

Statistics referred to dummy variables (with the exception of Age) for 973 observations.

Concerning internationalization, a binary variable is used, e.g. if a selected firm is internationalized, the related dummy takes value 1 (else 0 ). The low propensity to internationalization for Italian logistics firms is testified by the null value for the median and by a 0.2 value for the mean. Similarly, only a minor share of our sample is specialized in favour of a specific productive chain (specialization). Considering the age variable, the set of companies studied is in a maturity stage (mean age: 17 years; median age: 12 years). As for the type of corporations, limited companies largely prevail in the sample. It is worth noticing that other relevant external variables have been considered, as the GDP per capita and the infrastructure endowment. Nevertheless, the related coefficients proved not to be statistically significant, without any relevant effect on other covariates and for this reason we decided to exclude them from the analysis.

\subsection{First stage}

Logistics firms offer a wide range of heterogeneous services, such as transportation, goods distribution, packaging, value added services, etc. Given this heterogeneity, it is preferable exploiting a non-parametric 
method in order to avoid distortions due to a pre-determined production function, as discussed by Zhu (2016). DEA is one of the most widespread non-parametric methods to analyse both logistics and transportation sectors: this linear optimization technique compares different firms' performances (Decision Making Units - DMU) through their input and output profile (see Wanke 2012a and 2012b; Basta and Ferrari 2010; Cullinane and Wang, 2007; Min and Joo 2006). DEA selects the firms that, given a certain input mix, maximize their output (or, vice versa, given a certain output, are able to minimize their input mix), and in accordance with the aim of the analysis - output maximization or input minimization - input oriented or output oriented DEA models may be used, respectively. After identifying the efficient firms' set, it is possible to define the efficiency frontier, and efficiency scores are given taking into account the distance of each firm from this frontier: these scores reflect efficiency in relative terms and the distance allows to carry out a correct comparison only within the selected sample or among homogeneous groups of DMUs (as possible in our case with the selected time windows).

DEA was firstly introduced by Koopmans (1951) and Farrel (1957) and the formulation used in this papers is based on the development introduced by Banker et al. (1984) to study the efficiency levels under the hypothesis of variable returns to scale (VRS).

From a formal point of view, given $\mathrm{K}=1,2, \ldots, \mathrm{k}$ selected firms and $X^{k}=x_{1}^{k}, x_{2}^{k}, \ldots, x_{m}^{k}$ as the set of inputs with $Y^{k}=y_{1}^{k}, y_{2}^{k}, \ldots, y_{n}^{k}$ the related set of outputs and $\boldsymbol{\lambda}$ a non-negative matrix (i.e. with all the elements $\lambda_{\mathrm{j}}$, nonnegative). The efficiency scores can be estimated through the following linear programming model:

$\min \theta$

subject to

$$
\begin{gathered}
\theta x k-X \lambda \geq 0 \\
Y \lambda \geq y k \\
\sum_{j=1}^{k} \lambda_{j}=1
\end{gathered}
$$

$$
\lambda_{j} \geq 0
$$


As said, solving the linear optimization model it is possible to identify efficiency scores for each included DMU.

As already mentioned, and in accordance with relevant literature, the analysis has been conducted using one output and four inputs: on the one hand it exploits firms' revenues and on the other hand labour, services, material costs and tangible fixed assets are the inputs considered.

Taking into account the possible distortions due to some outliers, the analysis has been carried out both with all the selected DMUs, and without those reporting excessively high or low values for inputs and output (outliers). In both cases, beyond some specific scores differences, the efficiency trend and average level look very similar, giving robustness to our findings.

\subsection{Second stage}

In the second step of the analysis, the efficiency scores for each firm are used as dependent variable in a second stage regression based on the method proposed by Simar and Wilson (2007) ranging from simple OLS regressions to more sophisticated methods avoiding distorted outcomes. Recently several authors used multi-step approaches in order to better understand efficiency level and performance in different transport industries, such as maritime (e.g. Bang et al. 2012), ports (Bergantino and Musso 2010), airports (e.g. Gillen and Lall 1997), road transport (Wanke et al. 2014) and other service industries. Concerning possible distortion due to different approaches, it is important to underline that several authors discussed this matter (e.g. Daraio and Simar 2005, Simar and Wilson 2007) underlining potential biases of using parametric or non-parametric estimations. While the debate is still open, OLS seems unbiased providing consistent estimators, in case of large samples, as in our case.

Thus, following De Oliveira and Cariou (2014), we exploit a truncated bootstrapped regression that iterates the estimates, in order to identify the statistics distribution where unknown, due to the sampling design (Green, 2008). Since a cluster analysis is used, the Simar and Wilson (2007) bootstrapped regression remove the potential estimates distortion for the two-stage approach that is debated in literature. This distortion may come from the eventual high correlation among the second stage explicative variables, the efficiency 
scores and the inputs and outputs used for the DEA (however we observed a very low correlations among our variables, through the correlogram). Thus, the second stage is formed by the following regression:

$$
D E A_{k}=\beta z_{k}+\varepsilon_{k}
$$

where DEA represents the efficiency score for the $k^{\text {th }} \mathrm{DMU}$, and $z$ stays for the set of firms' specific variables, potentially impacting on efficiency, while $\varepsilon$ represents the error term.

The second stage estimation aims at determining the possible relations among efficiency scores and firms' conditioning variables $(z)$. Keeping in mind the available micro-data and the literature about the main firms' features impacting on DMUs' productivity, the following variables were selected: size, specialization, internationalization, age, geographical localization and type of corporation. These covariates are not exhaustive, since other possible explicative variables may exert some influence on firms' efficiency (e.g. for the variable "internationalization" it should be preferable to use continuous variables such as export revenues, but data are not available, since this is a common missing variable for most of the firms included in specialised databases).

\section{Results and discussion}

According to the outcomes of the first stage analysis, the mean efficiency for our sample exhibits a decreasing trend during the period 2006-2012, even with a rebound starting from 2010. By using a "closed sample" we are able to check for the efficiency evolution over the studied period; however, the average efficiency level probably overestimates the real Italian logistics performance (as also underlined by Ferrari et al. 2013) given the exclusion of the companies that are not consistently present in the database.

Looking at table 3, the VRS-DEA analysis reports a progressive growth for the number of efficient DMUs till 2010 and a decreasing trend in the following two years. 


\begin{tabular}{|c|c|c|c|c|c|c|c|}
\hline & 2006 & 2007 & 2008 & 2009 & 2010 & 2011 & 2012 \\
\hline Efficient DMU & 45 & 49 & 48 & 50 & 57 & 53 & 49 \\
\hline Min & 0.494 & 0.437 & 0.501 & 0.410 & 0.485 & 0.339 & 0.521 \\
\hline MAX & 1.000 & 1.000 & 1.000 & 1.000 & 1.000 & 1.000 & 1.000 \\
\hline Variance & 0.008 & 0.010 & 0.006 & 0.021 & 0.008 & 0.013 & 0.011 \\
\hline Mean & 0.925 & 0.921 & 0.942 & 0.877 & 0.929 & 0.912 & 0.920 \\
\hline
\end{tabular}

An efficiency gap may depend on technical features or in a not-optimal size with respect to the market features. That is why efficiency scores are split into pure efficiency and scale efficiency scores. The VRS-DEA scores represent the pure efficiency, while the scale efficiency scores are produced by the ratio between the CRS-DEA and the VRS-DEA scores. Scale efficiency results are shown in table 4.

We find that scale efficiency exhibits the same trend as the pure efficiency (see table 3), even if a higher number of DMUs do not reach an optimal scale; we conclude that scale efficiency is one of the main causes for Italian logistics firms' inefficiency. Moreover, also Ferrari et al. (2013) - by carrying out a specific return to scale analysis - demonstrated a need for a different size for Italian logistics firms, in order to exploit potential economies of scale.

Table 4: Scale efficiency summary

\begin{tabular}{c|ccccccc}
\multicolumn{2}{c}{2006} & 2007 & 2008 & 2009 & 2010 & 2011 & 2012 \\
\hline Scale efficiency (mean) & 0.963 & 0.968 & 0.969 & 0.895 & 0.956 & 0.954 & 0.954 \\
\% of efficient DMUs & 80 & 79 & 78 & 86 & 80 & 78 & 79
\end{tabular}

The efficiency trends for the four Italian macro-region, appear to be rather consistent with the national trend apart some (small) differences. For the North East, for example, despite the fluctuations, efficiency shows a slight reduction over the period and at the end of the 2012, this is the region with the lowest efficiency scores. The North West too registers a small decrease. On the contrary, even if struck by the economic crisis, the Centre and the South of Italy exhibit a small increase for efficiency level. But if we look at the mean efficiency score for the overall period, instead of the seven years trend, we find that the North 
West is the best performing area (mean efficiency: 0.937), while the South shows the worst results (0.894); the Centre (0.925) and the North East (0.909) stay in intermediate positions.

Figure 4: efficiency trend by geographical areas

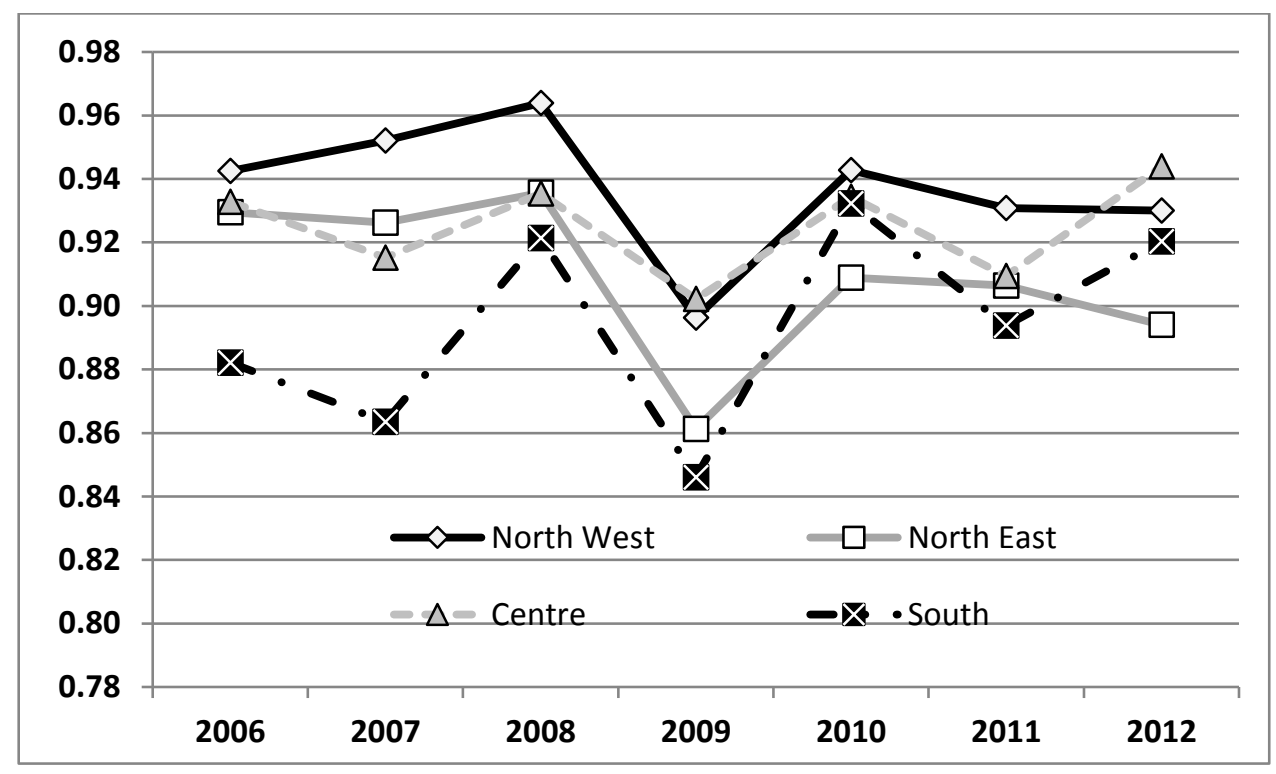

Source: Our elaboration on Cebil-Cerved data.

Moreover, the large majority of efficient DMUs stays in the North West. Starting from the second half of the considered period we observe a reduction in the number of efficient DMUs, especially in the Northern regions, while an increase is registered for the South located firms. 


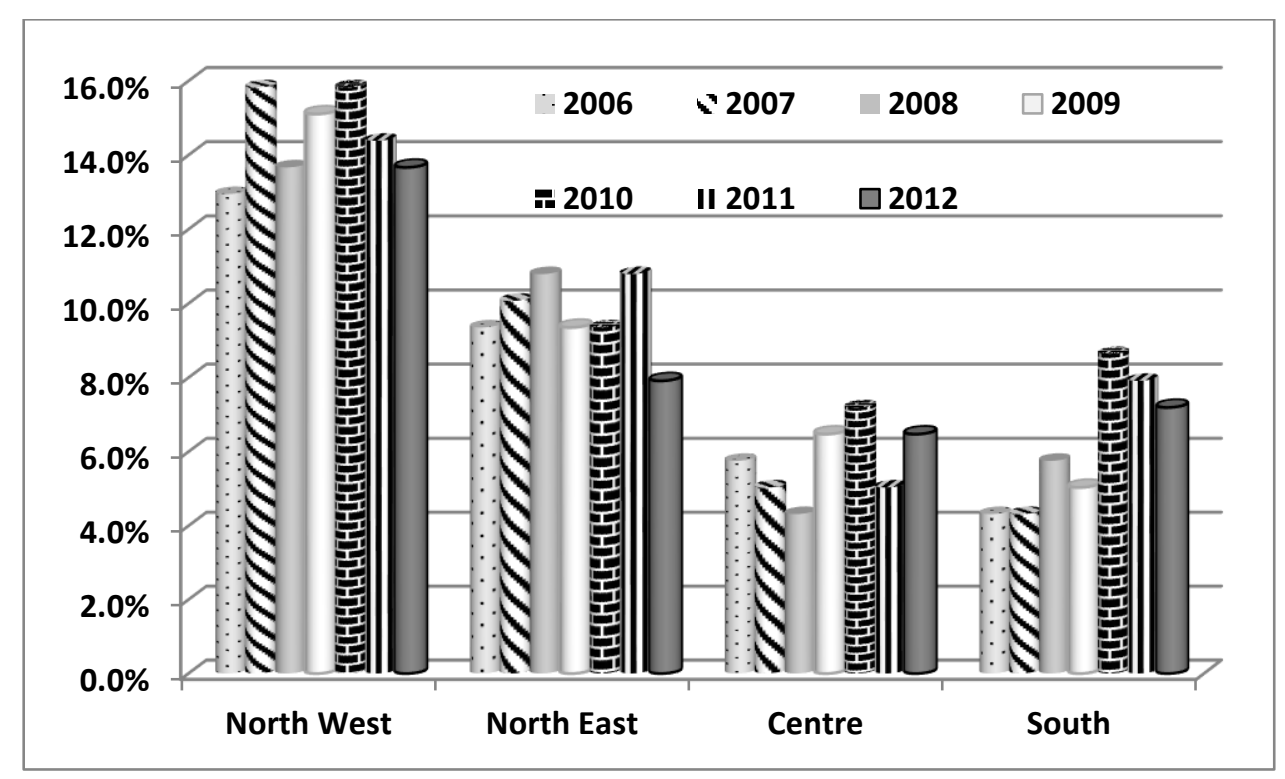

Source: Our elaboration on Cebil-Cerved data.

To identify the possible impact of firms' size on efficiency, we divided our sample between the large firms (or those with revenues above median of the sample) and small and medium enterprises (SMEs; having revenues under the sample median). Two distinct DEA analyses were carried out on these subsamples whose results are summarized in figure 6. The large firms always perform better than the SMEs; moreover, large firms show more stable results over the seven years and proved to be resilient also at the crisis climax.

Figure 6: efficiency scores by firms' size

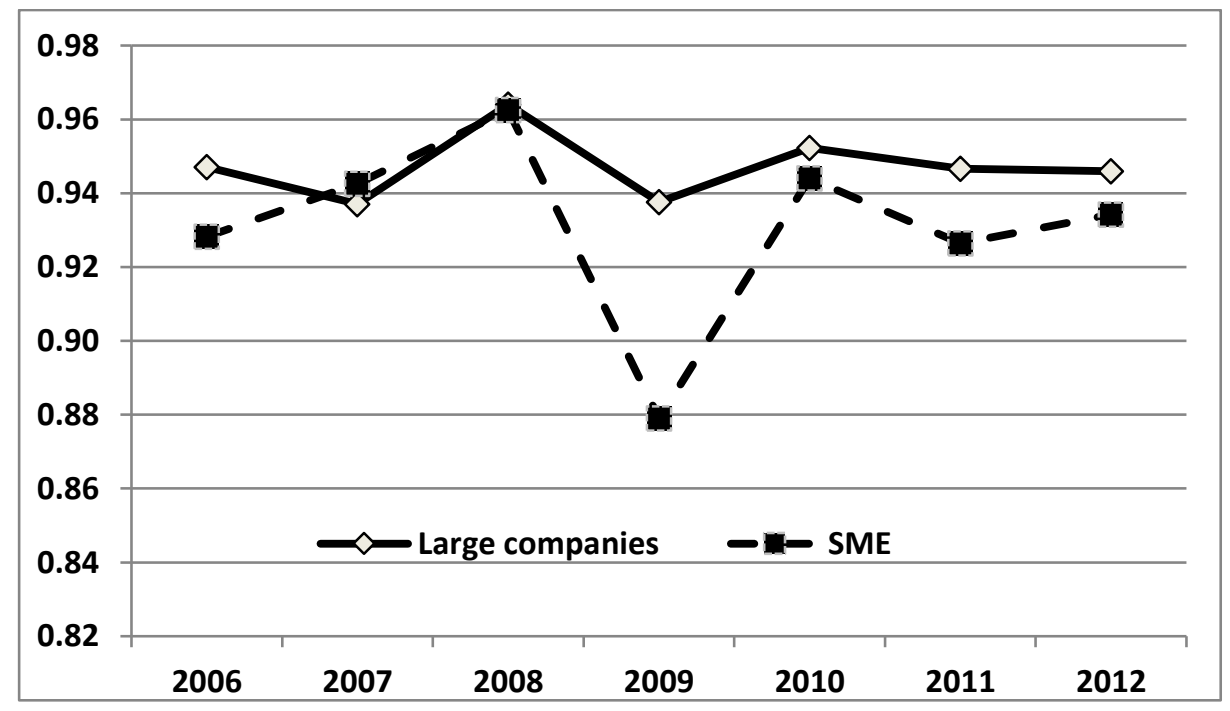

Source: Our elaboration on Cebil-Cerved data. 
Table 5 summarizes the results coming from the second stage.

\section{Table 5: regression results}

\begin{tabular}{|c|c|c|c|c|c|}
\hline VARIABLES & ITALY & $\begin{array}{l}\text { NORTH } \\
\text { WEST }\end{array}$ & $\begin{array}{l}\text { NORTH } \\
\text { EAST }\end{array}$ & CENTRE & SOUTH \\
\hline D_int & $\begin{array}{c}0.0323 \\
(0.0544)\end{array}$ & $\begin{array}{l}0.0574^{*} \\
(0.0323)\end{array}$ & $\begin{array}{l}-0.0489 \\
(0.1171)\end{array}$ & $\begin{array}{c}0.0569 \\
(0.0371)\end{array}$ & Om. \\
\hline D_spec & $\begin{array}{l}-0.0640^{*} \\
(0.0367)\end{array}$ & $\begin{array}{c}0.0007 \\
(0.0633)\end{array}$ & $\begin{array}{l}-0.0646 \\
(0.0671)\end{array}$ & $\begin{array}{c}-0.0292 \\
(0.0275)\end{array}$ & $\begin{array}{l}-0.0759 \\
(0.2510)\end{array}$ \\
\hline Age & $\begin{array}{c}-0.00379^{\star * *} \\
(0.00127)\end{array}$ & $\begin{array}{c}-0.00172 \\
(0.0013)\end{array}$ & $\begin{array}{l}-0.0034 \\
(0.0030)\end{array}$ & $\begin{array}{l}-0.0013 \\
(0.0012)\end{array}$ & $\begin{array}{l}-0.0036 \\
(0.0172)\end{array}$ \\
\hline D_dim & $\begin{array}{l}0.171^{* * *} \\
(0.0467)\end{array}$ & $\begin{array}{c}0.1274^{* * *} \\
(0.0441)\end{array}$ & $\begin{array}{c}0.2078^{\star * *} \\
(0.0774)\end{array}$ & $\begin{array}{l}0.0769^{* *} \\
(0.3042)\end{array}$ & $\begin{array}{c}0.1439 \\
(0.2378)\end{array}$ \\
\hline D_fg & $\begin{array}{l}-0.0617 \\
(0.0595)\end{array}$ & $\begin{array}{l}-0.0207 \\
(0.0864)\end{array}$ & $\begin{array}{l}-0.1008 \\
(0.0834)\end{array}$ & $\begin{array}{c}0.0223 \\
(0.0389)\end{array}$ & $\begin{array}{l}-0.2802 \\
(1.3455)\end{array}$ \\
\hline Areas Dummy & yes & no & no & no & no \\
\hline Years Dummy & yes & yes & yes & yes & yes \\
\hline Constant & $\begin{array}{l}1.155^{\star * *} \\
(0.0882)\end{array}$ & $\begin{array}{l}0.964^{* * *} \\
(0.0859)\end{array}$ & $\begin{array}{l}1.155^{\star * *} \\
(0.123)\end{array}$ & $\begin{array}{l}0.893^{* * *} \\
(0.0437)\end{array}$ & $\begin{array}{c}1,485 \\
(1.421)\end{array}$ \\
\hline Observations & 622 & 174 & 207 & 119 & 122 \\
\hline Wald chi2(14) & 43.91 & 27.46 & 25.76 & 41.05 & 6.05 \\
\hline
\end{tabular}

Robust standard errors in parenthesis*** $\mathrm{p}<0.01, * * \mathrm{p}<0.05, * \mathrm{p}<0.1$.

Truncated Regression. Bootstrap replications (2000) based on 121 clusters.

Looking at table 5, first we find that size has a positive and statistically significant effect, so that, on average, firms with revenues over the sample median show higher efficiency scores. Other two explicative variables show statistically significant coefficients, the first at a 1 per cent and the second at a 5 per cent confidence interval. On the one hand the variable age has a negative but very low coefficient; indeed, on average longlived firms exhibit lower efficiency during the crisis, presumably reacting slowly to a changed market scenario. On the other hand, the variable specialization registers a negative effect on efficiency: being specialized to support a specific productive chain might represent a weakness in the depression phase of the business cycle, while a diversification strategy contributes to increase the efficiency score. 
On the other hand, the variables type of corporation and internationalization register non-significant impact on efficiency. Considering the first covariate, Ferrari et al. (2013) identified on a descriptive point of view a better performance for cooperative firms; starting from that observation, we replaced our dummy variable, distinguishing between limited corporations and other forms of corporations, with a variable assuming different values for each specific different Italian type of corporation (limited companies, limited liability companies, cooperative companies and consortia). The related regression confirms that cooperative companies are the most efficient, but coefficients are just under the 10 per cent threshold for the statistics robustness.

In relation to the variable internationalization, few firms out of the sample (20\%) are internationalized (dummy: 1); these firms are mostly concentrated in the North-West of Italy. Moreover, we replaced the covariate internationalization with a variable called Multinational (proxing firms belonging to a multinational group), in order to control for a possible impact on efficiency, but again the coefficient is not statistically significant.

Our second stage regression results show that firms in the South of the country are less efficient, while the Years dummies reflect the economic cycle evolution (the demand collapse largely impacted on the efficiency fall for the year 2009).

Moreover, to check the robustness of results, the analysis was repeated excluding the sample's outliers. Again, we find that size impacts on efficiency, while age has a negative effect on the firms' ability to react to a negative economic conjuncture, even if very low (in this latter case the coefficient for the variable specialization registers a statistics robustness loss).

Finally, the analysis was repeated for each Italian macro-region to check for the impact of the explicative variables across geographic location. The outcomes depend also by the heterogeneous distribution of the sample across the country; all in all we find again that size is the most impacting variable (except for the South), while age and specialization lose statistics significance; in the North West, where is located the large majority of internationalized firms, also the dummy internationalization has a positive effect on efficiency. 


\subsection{Insights for practitioners}

Current study showed how efficiency depends on some company characteristics and how specific strategies (e.g. specialization), general elements (e.g. age) and external characteristics (e.g. location) can impact on the achievable level of efficiency. For this reason, the results seem to suggest that every company, in the aim of pursuing an increasing level of efficiency, should take into account different "environmental" factors and not only internal characteristics (such as the industrial process). In fact, while the DEA outcome is linked to the input-output ratio, the fact that the second stage was able to identify a clear connection between some external variables and the level of efficiency refers to those external elements that the industry should identify outside the normal production process in order to increase its efficiency. This fact seems to be even more important during the period of economic crisis, as the period of time analyzed in the study. In order to achieve this goal, every logistics company should, for instance, increases its competitive position in serving a specific market (i.e. specialization) more than diversifying its set of clients. This result seems quite interesting in a period of increasing innovations and tendency of logistics diversification. In fact, while global players try to compete in various markets, results suggest that the specialization on a specific supply chain could create a competitive advantage for many companies, at least in terms of firm efficiency. Moreover, while some factors are completely exogenous for the company and cannot be modified (in the short run) by managers (e.g. location) some others (i.e. age) reflect a more conservative approach of firms and a difficulty to innovate the companies' products: this can impact on the level of efficiency, as also suggested by Marchet et al. (2016).

\section{Concluding remarks}

Logistics is becoming a major fundamental economic sector not only as an industry itself but mainly for its contribution to featuring manufacturing firms' productivity. This is the reason why we investigated the Italian logistics industry through an analysis based on a two-stage methodology aiming at (i) estimating the Italian logistics firms efficiency and (ii) defining - and possibly measuring - some characteristics impacting 
on the efficiency level. This double-stage approach has been rarely applied to similar problems and allows the study to find main efficiency drivers (in terms of I-O) and environmental variables.

On a first stage the analysis focuses on Italian logistics providers by exploiting a Data Envelopment Analysis based on 2006-2012 balance sheets figures. According to our main findings, Italian logistics providers do not suffer by relevant efficiency gaps, but the economic crisis that took place in 2008 has weakened the industry's efficiency, due to the diminishing demand for services (registered in 2009 especially). Moreover, in accordance with the recent literature and using a new methodology to investigate the firms' efficiency, we checked for the role of some firms' specific factors on their performance.

The second stage analysis - even if not exhaustive (due to the available data that do not cover all the possible variables impacting on firms' efficiency) - shows that firms located in the South of Italy underperformed in terms of efficiency scores in comparison with others Italian macro-regions (however Years dummy registers a statistically significant and negative coefficient for the years 2009 and 2011, when the crisis was more severe). Second, small and medium enterprises performed worse and they suffered more than big companies from the economic crisis. These outcomes are coherent with the findings showed by Ferrari et al. (2013) that - analysing the period 2006-2010 - shed light on what follows: logistics firms' efficiency exhibited a small decrease, due to the demand fall determined by the economic crisis; firms located in the South register lower efficiency scores; cooperative firms performed better, having lower tangible fixed assets and more flexible labour force; finally, large firms appeared more efficient and were more resilient to the adverse economic conjuncture. Long-lived firms (the variable "age" in our model) register lower efficiency scores (in comparison with the rest of the sample) this implies that firms well established in the market are more conservative and react less rapidly to a diminishing demand). Being specialized to offer logistics services in favor of a specific industrial chain resulted as a weakness point for efficiency (the unfavorable business cycle may determine a fall in the demand for specific industrial chains, not compensated by an adequate diversification for supply). Moreover, in the North-West, the region that host about $60 \%$ of internationalized firms, the variable internationalization has a positive impact on efficiency. Finally, three other possible covariates - being part of a multinational group; the NUTS-3 level 
per capita GDP; and the NUTS-3 level of infrastructural endowment - do not robustly conditioned the efficiency level (for the two latter variables, due also to the low variability of data along the considered time period). It is interesting to underline how these results seem consistent also with another recent study (i.e., Marchet et al. 2016) that pointed out a link between efficiency and innovation in Italian 3PL firms even though current study is more focused on strategic elements (such as specialization, company size and others) than services quality (such as the capability to offer innovative solutions to the clients).

The study not only shows the regional gap of logistics providers, for instance in terms of size, but underlines main characteristics that impact on the logistics efficiency level: size, flexibility and possibility to be part of an international network. Where these factors are more common, logistics providers perform better and are more resilient to the economic crisis.

The methodology applied in this research - combining DEA with a bootstrapped regression analysis - gives useful insights on the role that some environmental characteristics have on the economic efficiency of logistics providers across the country. On this regard, the results of this study might be useful in order to better understand incentives or other policy tools aiming at improving the national logistics sector. In particular, this study highlights how the existence of a fragmented industry, where the model of the small firms is still prevalent, undermines the economic performances of the industry itself and does not properly support a manufacturing sector structured on firms geographically dispersed and demanding high service quality.

Being aware of the limitations of the study (e.g. potential use of different data to estimate some external elements [e.g. export] or the substitution of regression with a Tobit estimation), nevertheless these results may be useful to further investigate the optimal size for logistics firms and other aspects, such as the capability to promptly react to a change in market conditions, the ability to diversify business in favor of other destination markets or industrial chains and the propensity to offer services at an international scale. Moreover, further development will focus on the possibility to better understand the effects of collaboration among the logistics companies as well as the performance of the service network. 


\section{References}

Altug M.S., T. Aydiniliyim. 2016. Counteracting Strategic Purchase Deferrals: The Impact of Online Retailers' Return Policy Decisions. Manufacturing \& Service Operations Management 18 376-392.

Balaguer-Coll M.T., E. Prior, E. Tortosa-Ausina. 2007. On the Determinants of Local Government Performance: A Two-stage Nonparametric Approach. European Economic Review 51 425-451.

Bang H.S., H.W. Kang, J. Martin, S.H. Woo. 2012. The impact of operational and strategic management on liner shipping efficiency: a two-stage DEA approach. Maritime Policy \& Management 39 653-672.

Banker R.D., A. Charnes, W.W. Cooper. 1984. Some models for estimating technical and scale inefficiencies. Management Science 39 1078-1092.

Barnum D.T., J.M. Gleason. 2008. Bias and Precision in the DEA Two-stage Method. Applied Economics 40 2305-2311.

Basta M., C. Ferrari. 2010. Port concession fees based on the price-cap regulation: A DEA approach. Maritime Economics and Logistics 11 121-135.

Bergantino A.S., C. Capozza, F. Porcelli. 2013. Measuring Teaching Efficiency of the Italian University System: the Role of Market Structure. A two-step DEA analysis at faculty level. Proceedings of the XXV conference SIEPI, Ancona Italy.

Bergantino A.S., E. Musso. 2010. A multi-step approach to model the relative efficiency of European ports: the role of regulation and other non-discretionary factors. In: CULLINANE K. The international handbook of maritime economics, 383-404, Edward Elgar Publishing Limited, Cheltenham.

Bolumole Y.A., D.J. Closs, F.A. Rodammer. 2015. The economic development role of regional logistics hubs: a cross-country study of interorganizational governance models. Journal of Business Logistics 36 182-198. Bottani E., A. Rizzi, G. Vignali. 2015. Improving logistics efficiency of industrial districts: a framework and case study in the food sector. International Journal of Logistics Research and Applications 5 402-423. Bracalente B., P. Polinori. 2010. Technical and economic efficiency of local public services: the cases of the municipals pharmacies and of the integrated waste services MPRA Paper N. 34455 Munich. 
Buzzo Margari B., F. Erbetta, C. Petraglia, M. Piacenza. 2007. Regulatory and Environmental Effects on Public Transit Efficiency: A Mixed DEA-SFA Approach. Journal of Regulatory Economics 32 131-151.

Clark X., D. Dollar, A. Micco. 2004. Port efficiency, maritime transport costs, and bilateral trade. Journal of Development Economics 75 417-450.

Clifton C., A. Iyer, R. Cho, W. Jiang, M. Kantarcioglu, J. Vaidya. 2006. An Approach to Securely Identifying Beneficial Collaboration in Decentralized Logistics Systems. Manufacturing \& Service Operations Management 10 108-125.

Confetra. 2009. Analisi strutturale delle imprese nel settore dei servizi logistici e di trasporto 2007. Rome Italy.

Confetra. 2011. La logistica italiana, Rapporto della 66a Assemblea Annuale. Rome Italy.

Council of Logistic Management. 1998. http://www.logisticsworld.com/logistics.htm.

Cullinane K., Wang T.F. 2007. The efficiency of European container ports: A cross-sectional data envelopment analysis. International Journal of Logistics Research and Applications 9 19-31.

Daraio C., L. Simar. 2005. Introducing environmental variables in nonparametric frontier models: A probabilistic approach. Journal of Productivity Analysis 24 93-121.

Dayou C. 2010. Evaluating the Profitability and Marketability of Logistics Companies in China Based on Twostage DEA. Proceedings of the 2010 International Conference of Information Science and Management Engineering, Xi'an China.

De Oliveira F.G., P. Cariou. 2014. The Impact of Competition on Container Port (In)efficiency. Proceedings of the 2014 conference IAME, Norfolk USA.

Farrell M.J. 1957. The measurement of productive efficiency. Journal of the Royal Statistical Society, Series A $120253-281$.

Ferrari C., A. Migliardi, A. Tei. 2013. L'efficienza delle aziende logistiche italiane. Economia dei Servizi 2 147160.

Fugato B., D.J. Flint, D. Mentzer. 2008. The role of logistics in market orientation. Journal of Business Logistics 29 1-26. 
Fugate B.S., J.T. Mentzer, T.P. Stank. 2010. Logistics Performance: Efficiency, effectiveness, and differentiation. Journal of Business Logistics 31 43-62.

Garland Chow G., T. Heaver, L. Henriksson. 1994. Logistics Performance. International Journal of Physical Distribution \& Logistics Management 24 1-28.

Gillen D., A. Lall. 1997. Developing measures of airport productivity and performance: An application of data envelopment analysis. Transportation Research Part E 33 261-274.

Green W.H. 2008. Econometric Analysis, Pearson, New Jersey USA.

Groer C., B. Golden, E. Wasil. 2008. The Consistent Vehicle Routing Problem. Manufacturing \& Service Operations Management 11 630-643.

Giffis S.E., T.J. Goldsby, M. Cooper, D.J. Closs. 2007. Aligning logistics performance measures to the information needs of the firm. Journal of Business Logistics 28 35-56.

Halley A., A. Guilhon. 1997. Logistics behaviour of small enterprises: performance, strategy and definition. International Journal of Physical Distribution \& Logistics Management 27 475-495.

lannone F. 2012. The private and social cost efficiency of port hinterland container distribution through a regional logistics system. Transportation Research Part A 46 1424-1448.

Istituto Tagliacarne. 2015. Atlante della competitività delle Province e delle Regioni (2007-2014), http://www.tagliacarne.it/

Koopmans T.C. 1951. Activity analysis of production and allocation, Cowles Commission for Research in Economics 13, Wiley New York.

Kumbhakar S.C., C.A.K. Lovell. 2000. Stochastic Frontier Analysis, Cambridge University Press, Cambridge United Kingdom.

Liu B., S. Fu. 2009. Efficiency Measurement of Logistics Public Companies Basing on the Modified DEA Model. Proceedings of the 2009 International Conference on Computational Intelligence and Security, Beijing China.

Marchet G., Melacini M., Sassi C., Tappia E. 2016. Assessing efficiency and innovation in the 3PL industry: an empirical analysis. International Journal of Logistics Research and Applications, online access. 
Min H., S. Joo. 2006. Benchmarking the operational efficiency of major third party logistics providers using data envelopment analysis. Supply Chain Management: An International Journal 11 259-265.

Min H., S. Joo 2009. Benchmarking third party logistics providers using data envelopment analysis: an update. Benchmarking: An International Journal 16 572-587.

Momeni E., M. Azadi, R.F. Saen. 2015. Measuring the efficiency of third party reverse logistics provider in supply chain by multi objective additive network DEA model. International Journal of Shipping and Transport Logistics 7 21-41.

Pagliaro B. 2013. Senza Rete. Infrastrutture in Italia: cronache del cambiamento. Edizioni Angelo Guerini e Ass., Milan Italy.

Simar L., P. Wilson. 2007. Estimation and inference in two-stage, semi-parametric models of production processes. Journal of Econometrics 136 31-64.

Skjoett-Larsen T. 2000. Third party logistics - from an interorganizational point of view. International Journal of Physical Distribution \& Logistics Management 30 112-127.

Stecke K., J. Zhao. 2007. Production and Transportation Integration for a Make-to-Order Manufacturing Company with a Commit-to-Delivery Business Mode. Manufacturing \& Service Operations Management 9 206-224.

Wanke P.F. 2012b. Determinants of Scale Efficiency in the Brazilian Third-Party Logistics Industry from 2001 to 2009. Brazilian Administration Review $966-87$.

Wanke P.F, C.P. Barros, O. Figueiredo. 2014. Measuring efficiency improvement in Brazilian trucking: A Distance Friction Minimization approach with fixed factors. Measurement (London) 54 166-177.

Wanke P.F. 2012a. Determinants of scale efficiency in the Brazilian 3PL industry: a 10-year analysis. International Journal of Production Research 50 2423-2438.

Wanke P.F. 2010. Determinants of Scale Efficiency in the Brazilian 3PL Industry from 2001 to 2008. International Journal of Logistics Economics and Globalisation 2 217-232.

Wanke, P.F. 2014. Efficiency drivers in the Brazilian trucking industry: a longitudinal study from 2002-2010. International Journal of Physical Distribution \& Logistics Management 44 540-558. 
Zhou G., H. Min, C. Xu, Z. Cao. 2008. Evaluating the comparative efficiency of Chinese third party logistics providers using data envelopment analysis. International Journal of Physical Distribution \& Logistics Management. 38 262-279.

Zhu J. 2016. Data Envelopment Analysis: A Handbook of Empirical Studies and Applications. Springer, New York USA. 